\title{
Engineering Bone Formation from Human Dental Pulp- and Periodontal Ligament-Derived Cells
}

Hideyoshi Ikeda, ${ }^{1}$ Yoshinori Sumita, ${ }^{1}$ Minoko Ikeda, ${ }^{1}$ Hisazumi Ikeda, ${ }^{1}$ Teruhito

Okumura, ${ }^{1}$ Eiko Sakai, ${ }^{2}$ Masahiro Nishimura, ${ }^{3}$ and Izumi Asahina $^{1}$

${ }^{1}$ Department of Regenerative Oral Surgery, Unit of Translational Medicine, Nagasaki

University Graduate School of Biomedical Sciences, Nagasaki, Japan; ${ }^{2}$ Department of

Oral Pathopharmacology, Unit of Basic Medical Sciences, Nagasaki University

Graduate School of Biomedical Sciences, Nagasaki, Japan; ${ }^{3}$ Department of Prostheic

Dentistry, Unit of Translational Medicine, Nagasaki University Graduate School of

Biomedical Sciences, Nagasaki, Japan

Address correspondence to Izumi Asahina, Department of Regenerative Oral Surgery, Unit of Translational Medicine, Nagasaki University Graduate School of Biomedical Sciences, 1-7-1 Sakamoto, Nagasaki 852-8588, Japan. Tel: +81 95819 7704; Fax: +81 95819 7705; E-mail address: asahina@nagasaki-u.ac.jp 
Abstract-A robust method for inducing bone formation from cultured dental mesenchymal cells has not been established. In the present study, an efficient method for generating bone tissue from cultured human dental pulp- and periodontal ligament-derived cells (DPCs and PDLCs, respectively) was designed using exogenous bone morphogenetic protein 2 (BMP2). DPCs and PDLCs showed enhanced alkaline phosphatase (ALP) activity and calcified nodule formation in medium containing dexamethasone, $\beta$-glycerophosphate, and ascorbic acid (osteogenic medium). However, the addition of recombinant human (rh) BMP2 to osteogenic medium remarkably increased ALP activity and in vitro calcification above the increases observed with osteogenic medium alone. rhBMP2 also significantly upregulated the expression of osteocalcin, osteopontin, and dentin matrix protein $1 \mathrm{mRNA}$ in both cell types cultured in osteogenic medium. Finally, we detected prominent bone-like tissue formation in vivo when cells had been exposed to rhBMP2 in osteogenic medium. In contrast, treatments with osteogenic medium or rhBMP2 alone could not induce abundant mineralized tissue formation. We propose here that treatment with rhBMP2 in osteogenic medium can make dental mesenchymal tissues a highly useful source of cells for bone tissue engineering. In addition, both DPCs and PDLCs showed similar and remarkable osteo-inducibility. 
Keywords-Dental pulp, Periodontal ligament, BMP2, In vivo bone formation, Tissue engineering

\section{INTRODUCTION}

Bone defects due to disease or trauma that do not heal spontaneously require bone reconstruction to restore bone function. Autografting and artificial bone substitution are currently performed, but results are inconsistent because autografts involve donor site morbidity and materials lack osteogenic potential. Recently, tissue engineering has attracted considerable attention, and bone regeneration using mesenchymal stem cells (MSCs) has been studied extensively. ${ }^{1,17,19,31,33}$ Because it requires only a small amount of tissue from the patient, bone reconstruction by this technique is less invasive and safer than conventional methods. To date, bone marrow or periosteum has been frequently used as a cell source for this strategy. ${ }^{1,4,25}$ However, although it has been shown that the MSCs in dental pulp and periodontal ligaments have similar properties as those in bone marrow ${ }^{6,29}$, efficient methods for generating bone tissue from dental mesenchymal cells have not been established.

Currently, dental pulp- and periodontal ligament-derived cells (DPCs and PDLCs) are receiving attention as cellular reservoirs for bone tissue engineering, because these cells supply mineralized dental tissues such as dentin, cementum, and alveolar bone. 
Previous studies have indicated that DPCs and PDLCs possess the potential to form mineralized nodules in vitro and express osteoblastic characteristics. ${ }^{5,9,27,28}$ Therefore, the use of DPCs and PDLCs is of great interest in bone tissue engineering, particularly in the oral and maxillofacial area, because they can be easily harvested without morbidity for dentists and expanded in culture. Nevertheless, while many previous studies gave the rise of their osteogenic potential in vitro, their inducibility for in vivo bone formation has not been examined well yet.

The aim of the present study is to take a step towards establishing suitable culture conditions to realize the bone generation from dental mesenchymal cells. In this study, the osteo-inducibility of recombinant human bone morphogenetic protein 2 (rhBMP2) was investigated in cultured DPCs and PDLCs, and the osteogenic potential of both dental mesenchymal cell types was compared. Recently, rhBMP2 has been shown to enhance the effects of osteo-inductive supplements such as dexamethasone (Dex), $\beta$-glycerophosphate ( $\beta$-Gly), and ascorbic acid (AA) on osteogenic differentiation of mesenchymal bone marrow cells. ${ }^{13,14,16}$ Therefore, we attempted this condition to determine effective osteo-inductive conditions for human dental mesenchymal cells. 


\title{
MATERIALS AND METHODS
}

\author{
Samples and Cell Cultures
}

This study conformed to the tenets of the Declaration of Helsinki, and the protocol was approved by the Ethics Committee of Nagasaki University School of Dentistry. All subjects provided written informed consent.

Normal erupted or impacted third molars $(n=5)$ were collected from five patients (ages 18, 19, 21, 24, and 30 years; two males and three females) after tooth extraction. Dental pulp was gently removed from the root canal, minced with scalpels, and rinsed with PBS. Periodontal ligament was gently separated from the surface of the root, minced with scalpels, and rinsed with PBS. These procedures were performed within 3 hours of tooth extraction. The explants were plated into $10-\mathrm{cm}$ dishes containing $\alpha$-MEM (Nissui Centical Co. Ltd., Tokyo, Japan) supplemented with $10 \%$ fetal bovine serum (FBS), glutamine $(0.6 \mathrm{mg} / \mathrm{ml})$, penicillin (100 units $/ \mathrm{ml})$, and streptomycin $(100$ $\mathrm{mg} / \mathrm{ml}$ ), and were cultured at $37^{\circ} \mathrm{C}$ in $5 \% \mathrm{CO}_{2}$. The medium was replaced every 3 days. When the cultures reached $90 \%$ confluence, cells were passaged and re-plated in $150-\mathrm{cm}^{2}$ flasks. To ensure phenotypic uniformity, we used each cell lineage following the second passage in the subsequent experiments.

Cell proliferation assay 
The proliferation of each cell type was examined with a colorimetric [3-(4,5-dimethyl-2-thiazolyl)-2,5-diphenyl-2H-tetrazolium bromide] (MTT) assay. In brief, both cell types were cultured with serum-conditioned $\alpha$-MEM in 96-well plates at an initial density of $1.0 \times 10^{4}$ cells per well. On days $1,3,5,7$ and 9 , cells were treated with $10 \mu \mathrm{l}$ of MTT solution (5 mg MTT per $1 \mathrm{ml}$ PBS), which was added to each well and incubated at $37^{\circ} \mathrm{C}$ for 4 hours. Finally, $100 \mu$ acid-isopropanol was added to each well to solubilize the MTT-formazan product. After complete solubilization of the dye, the absorbance was read on an Immuno reader (Immuno reader NJ-2000, Nihon Inter Med, Tokyo, Japan) at $570 \mathrm{~nm}$.

Alkaline phosphatase (ALP) activity assay

On day 0 , both cell types were plated at a density of $1.0 \times 10^{5}$ cells/well in 6 -well plates containing serum-conditioned $\alpha$-MEM. On day 1 , various concentrations of rhBMP2 $(0$, 30, 100, or $300 \mathrm{ng} / \mathrm{ml}$ ) (donated by Astellas Pharma Inc., Tokyo, Japan) were added to each well, along with serum-conditioned $\alpha$-MEM containing $10^{-8} \mathrm{M}$ Dex, $10 \mathrm{mM} \beta$-Gly, and $100 \mu \mathrm{M}$ AA (osteogenic medium). On days 4, 7, 10, and 13, medium was replaced with fresh medium containing identical osteo-inductive factors. On day 14, cells were harvested and extracted with $20 \mathrm{mM}$ HEPES buffer (pH 7.5) (Dojindo, Kumamoto, Japan) containing 1\% Triton X-100 (Wako, Osaka, Japan). ALP activity was assayed 
with $10 \mathrm{mM}$ (final) p-nitrophenyl phosphate as a subsrate in $50 \mathrm{mM}$ sodium carbonate buffer, $\mathrm{pH} 10$, containing $5 \mathrm{mM} \mathrm{MgCl}_{2}$. After $15 \mathrm{~min}$ of incubation at $37^{\circ} \mathrm{C}$, the reaction was stopped with $0.5 \mathrm{~N} \mathrm{NaOH}$ and absorbance was measured at $405 \mathrm{~nm}$. Protein in each sample was determined with the Bio Rad protein assay (Bio-Rad, Tokyo, Japan). ${ }^{3}$ ALP activity is expressed as $\mu \mathrm{mol} p$-nitrophenol $/ \mathrm{min} / \mu \mathrm{g} / \mathrm{protein}$.

\section{Alizarin red staining}

Both cell types were cultured in normal serum-conditioned $\alpha$-MEM, osteogenic medium, or osteogenic medium with $300 \mathrm{ng} / \mathrm{ml} \mathrm{rhBMP} 2$ for 14 days. On day 14, mineralization was assessed by staining with Alizarin red (Sigma-Aldrich, MO, USA). Briefly, $40 \mathrm{mM}$ of Alizarin red was prepared in distilled water and adjusted to $\mathrm{pH} 6.3$ with ammonium hydroxide. Cell layers were rinsed with PBS, fixed in $70 \%$ ethanol, and air dried. Then, cell layers were stained with Alizarin red at room temperature for 30 minutes. The cells were washed with distilled water and allowed to dry.

Reverse transcription-polymerase chain reaction (RT-PCR)

On day 0 , both cell types were plated in $10-\mathrm{cm}$ dishes containing serum-conditioned $\alpha$-MEM. Cells were treated with normal serum-conditioned $\alpha$-MEM, osteogenic medium, or osteogenic medium with $300 \mathrm{ng} / \mathrm{ml} \mathrm{rhBMP2}$ for 13 days. Media were replaced on days $1,4,7,10$, and 13 . On day 14 , total RNA was extracted using TRIZOL 
reagent (Invitrogen). RNA samples $(1 \mu \mathrm{g})$ were reverse-transcribed with RevetraAce ${ }^{\circledR}$ reverse-transcriptase and oligo-dT primers (Invitrogen), according to the manufacturer's protocol. To analyze gene expression, we used specific primers for PCR amplification as shown in Table 1. All primers used were obtained from Sigma-Aldrich Japan K.K. Life Science Division (Ishikari, Japan). After amplification, samples were analyzed by $2 \%$ agarose gel electrophoresis and visualized with ethidium bromide staining.

\section{Transplantation into immunodeficient mice}

For transplantation, $1 \times 10^{6}$ harvested cells (DPCs and PDLCs) in $1 \mathrm{ml}$ of $\alpha$-MEM supplemented with $10 \%$ FBS were mixed with $30 \mathrm{mg}$ of hydroxylapatite (HA) granules (APACERAM $=\mathrm{AX}^{\circledR}$; PENTAX, Tokyo, Japan), which size is from $0.6 \mathrm{~mm}$ to $1 \mathrm{~mm}$ with $50 \%$ porocity, in a 14-ml polypropylene tube. For the next 13 days, cells were cultured in [normal serum-conditioned $\alpha$-MEM], [normal serum-conditioned $\alpha$-MEM with 300ng/ml rhBMP2], [osteogenic medium], or [osteogenic medium with $300 \mathrm{ng} / \mathrm{ml}$ rhBMP2]. As a control, we used HA granules containing $300 \mathrm{ng} / \mathrm{ml}$ BMP2. The medium was replaced with fresh identical medium on days 4,7 , 10, and 13. After culturing, each cell mixture was transplanted into a 6-week-old female BALB/cAJcl-nu/nu mouse (Nihoncrea, Tokyo, Japan). Under anesthesia with diethyl ether, five subcutaneous pockets were created in the back of each mouse, and the cell-HA composites were 
transplanted. The transplants were harvested after 8 weeks. These procedures were performed in accordance with the institutional guidelines.

Histomorphometric analysis

The transplants were fixed with $10 \%$ formalin, decalcified with a solution containing $2.9 \%$ citric acid, $1.8 \%$ tri-sodium citrate dehydrate, $10 \%$ formic acid, and $90 \%$ distilled water, and embedded in paraffin wax. Sections $(3 \mu \mathrm{m})$ were deparaffinized and stained with hematoxylin and eosin. The volume of newly formed bone-like tissues was analyzed with NIH J Image software (NIH, Bethesda, MD, USA). The percentage of surface area occupied by bone-like tissues was assessed by light microscopy under $200 \times$ magnification using six sections from each of the five specimens. At least 10 fields per section were counted. The bone area is expressed as the percentage of the total area.

\section{Statistics}

All experimental values are presented as the mean \pm standard deviation. Means were analyzed using one-way analysis of variance. Dunnett's multiple comparison t-test was used to detect any significant differences within each group for cell proliferation, ALP activity, and percentage of bone area. 


\section{RESULTS}

Cell proliferation

DPCs and PDLCs showed similar morphology with a characteristic spindle shape, cell size, and monolayer appearance (Figs. 1a and $1 \mathrm{~b}$ ). The proliferation rate of both cell types was nearly identical (Fig. 1c). The number of PDLCs was similar to that of DPCs on days 1 and 3. At days 5, 7, and 9, the number of PDLCs was slightly greater than that of DPCs, but the difference was not statistically significant.

Alkaline phosphatase (ALP) activity

ALP activity of cultured DPCs and PDLCs was examined to determine the optimum differentiation conditions before the in vivo study. For the culture of DPCs, treatment with osteogenic medium significantly increased the ALP activity compared to control (non-treated) at day $14(p<0.05)$ (Fig. 2a). However, when rhBMP2 was added to the culture at concentrations of 100 and $300 \mathrm{ng} / \mathrm{ml}$, ALP activity was markedly enhanced over the effect of osteo-inductive supplements alone $(p<0.05)$ (Fig. 2a). rhBMP2 enhanced the ALP activity in a dose-dependent manner at concentrations of 30-300 ng/ml (Fig. 2a).

For the culture of PDLCs, osteogenic medium increased the ALP activity compared to control (non-treated) at day $14(p<0.05)$ (Fig. 2b). Moreover, the addition of 
rhBMP2 at concentrations of 100 and $300 \mathrm{ng} / \mathrm{ml}$ to the osteo-inductive supplements significantly enhanced the ALP activity $(p<0.05)$ (Fig. 2b). rhBMP2 enhanced the effect of osteogenic medium in a dose-dependent manner at concentrations of 30-300 ng/ml (Fig. 2b).

The basal ALP activity in PDLCs was approximately 2-fold higher than that in DPCs after 14 days of culture $(p<0.05)$ (Fig. 2). This tendency did not change even after treatment with rhBMP2.

Alizarin red staining

The formation of calcified nodules in cultures of DPCs and PDLCs was examined with Alizarin red staining for calcium, which showed vanishingly calcified nodules in both types of control cells (non-treated) after 14 days of culture (Figs. 3a and 3d). After treatment with osteogenic medium, calcified nodules were detectable in both cell types (Figs. $3 \mathrm{~b}$ and $3 \mathrm{e}$ ). However, the addition of $300 \mathrm{ng} / \mathrm{ml} \mathrm{rhBMP} 2$ remarkably increased calcified nodule formation in both types of cell cultures (Figs. 3c and 3f).

\section{Expression of osteoblastic marker genes}

The expression of osteoblastic marker genes was investigated in cultured DPCs and PDLCs in osteogenic medium with rhBMP2 (300 ng/ml). Non-treated DPCs expressed low levels of osteopontin (opn) and dentin matrix protein-1 (dmp-1), but did not express 
osteocalcin (ocn). When rhBMP2 with osteo-inductive supplements was added to the culture medium, DPCs upregulated their expression of opn and dmp-1, and began to express ocn (Fig. 4). Similarly, non-treated PDLCs also expressed low levels of opn and $d m p-1$, and did not express ocn. The expression of these genes was clearly observed after treatment in culture with osteogenic medium containing rhBMP2 (Fig. 4).

Histochemistry analysis 8 weeks after transplantation

Transplantation of HA alone did not cause formation of any new mineralized tissues (data not shown). Also, HA treated with $300 \mathrm{ng} / \mathrm{ml} \mathrm{rhBMP} 2$ alone without cells or HA containing non-treated cells (DPCs or PDLCs) did not form mineralized tissues (Figs. $5 \mathrm{a}, 5 \mathrm{~b}, 5 \mathrm{~g}$ and $5 \mathrm{~h})$. When the cells were treated with osteogenic medium, the hard tissues with osteocyte-like cell inclusions were observed inside the pores of HA along its structure, however the formation of such bone-like tissues was minimal (Figs. $5 \mathrm{c}$ and 5i). Similarly, bone-like tissue formation was observed in transplants of both cell types that had been treated with $300 \mathrm{ng} / \mathrm{ml}$ rhBMP2 without osteo-inductive supplements (Figs. $5 \mathrm{~d}$ and $5 \mathrm{j}$ ). On the other hand, abundant bone-like tissue formation was observed in transplants of both cell types that had been treated with osteogenic medium containing $300 \mathrm{ng} / \mathrm{ml} \mathrm{rhBMP2} \mathrm{(Figs.} \mathrm{5e,} \mathrm{5f,} \mathrm{5k} \mathrm{and} \mathrm{51).}$

The area occupied by bone-like tissue was compared in each specimen and 
each cell type. The areas occupied by bone-like tissue from transplants of DPCs and PDLCs treated with osteogenic medium containing rhBMP2 were approximately $56 \%$ and $61 \%$ of the whole area in a section, respectively (Fig. 6). Although no difference in the ability to form bone between DPCs and PDLCs was observed, the inducibility of both cell types following treatment with osteogenic medium containing rhBMP2 was remarkable. 


\section{DISCUSSION}

The results from the present study show that dental mesenchymal cells display prominent osteo-inducibility when treated with osteogenic medium containing rhBMP2.

The DPCs and PDLCs used in this study were obtained from extracted third molars from young patients. In the oral and maxillofacial area, there is a growing need to regenerate alveolar bone to treat periodontitis and for implant dentistry, and cell-based therapies are receiving increasing attention..$^{1,7,8,10,18,32}$ For dentists or oral surgeons, dental pulps and periodontal ligaments from discarded teeth, such as third molars, baby teeth that have fallen out, and premolars removed before orthodontic treatment are readily accessible and require an easy and minimally invasive procedure to obtain and store these tissues for future use..$^{9,11,21,23}$ Furthermore, banking a patient's own dental tissues is a reasonable and simple alternative to harvesting MSCs from other tissues. Recently, cryopreservation conditions have been optimized for banking human dental cells for future clinical use. ${ }^{2,30}$ Therefore, efficient methods for generating bone tissue from dental mesenchymal cells need to be developed rapidly. This study revealed that culturing DPCs and PDLCs in osteogenic medium containing rhBMP2 with HA granules induced abundant ectopic mineralized tissue formation in mice.

In cultures of DPCs and PDLCs, when $30-300 \mathrm{ng} / \mathrm{ml} \mathrm{rhBMP} 2$ was added to 
osteo-induction medium, ALP activity surpassed the increased ALP activity normally produced by osteo-induction alone. ALP activity is thought to be an appropriate early indicator of osteoblast differentiation in MSCs ${ }^{16,20}$, and our result suggests that rhBMP2 promotes the effects of osteo-inductive supplements to induce osteogenic differentiation from dental mesenchymal cells. Consistent with this result, rhBMP2 treatment induced remarkable calcified nodule formation in cultures of DPCs and PDLCs. Likewise, mRNA expression of osteogenic genes, such as ocn, opn, and dmp-1 was clearly upregulated in these cells after rhBMP2 treatment. This increased expression greatly surpassed the expression induced by osteogenic medium alone. In particular, ocn mRNA was markedly upregulated. Ocn is a bone-specific protein synthesized by osteoblasts during the mineralization period ${ }^{22}$, and its expression is regulated by $c b f a 1$, which is a major target gene of BMP2 signaling. ${ }^{16,27}$ Thus, these in vitro data demonstrated that rhBMP2 provides conspicuous inducibility of osteoblastic differentiation from dental mesenchymal cells.

Furthermore, we showed that DPCs and PDLCs generated abundant bone-like tissues in vivo when the cells were treated with rhBMP2. It was possible that rhBMP2 absorbed onto HA granules and induced ectopic bone formation. However, the implantation of HA granules treated with rhBMP2 without cells did not influence in 
vivo bone formation, ruling out this possibility. This result strongly supports the conclusion that rhBMP2 provides prominent osteo-inducibility of dental mesenchymal cell differentiation. Moreover, we observed only minimal mineralized tissue formation in samples treated only with osteogenic medium. These data suggest that the response of dental mesenchymal cells to added rhBMP2 is critical for generating bone tissue. On the other hand, the area occupied by bone-like tissues in specimens amounted to approximately $60 \%$ of the whole area. Although a direct comparison between dental mesenchymal cells and bone marrow cells used in previous studies suggests that the osteogenic potential of dental cells is inferior to that of bone marrow ${ }^{9}$, our result suggests that the potential of dental cells may be sufficient as a cell source when considering the availability and accessibility. Interestingly, there were no differences in the osteo-inducibility between DPCs and PDLCs when rhBMP2 was added to osteogenic medium. The histological appearance of their hard tissues, which showed bone-like tissue with osteocyte inclusions, was quite similar, though it has been reported that DPCs induce dentin-like tissue. ${ }^{12,26}$ Our finding suggests that both cell types contain a common osteoblast progenitor and can be used with a mixture of both cell types to regenerate bone from limited cell sources.

There are some reports of clinical studies that show successful bone regeneration 
following direct implantation of rhBMPs. ${ }^{15}$ However, implantation of high doses of rhBMP2 induces substantial swelling that may cause the obstruction of the airway when applied to oral and cervical areas. ${ }^{24}$ Compared to direct implantation, the bone engineering protocol presented in this study could be used to avoid this side effect of the growth factor because rhBMP2 is used only in vitro in our method. Furthermore, the amount of rhBMP2 required to induce bone formation may be less than one thousandth of that required for direct implantation, leading to cost efficiency when utilizing rhBMP2.

In conclusion, the present study demonstrates that rhBMP2 added to osteogenic medium can make both dental pulps and periodontal ligaments highly useful cell sources for alveolar bone tissue engineering. To develop bone engineering in the dental clinic, we highlight here the need for further studies promoting osteogenesis from DPCs or PDLCs. 


\section{REFERENCES}

${ }^{1}$ Agata, H., I. Asahina, Y. Yamazaki, M. Uchida, Y. Shinohara, M. J. Honda, H. Kagami, and M. Ueda. Effective bone engineering with periosteum-derived cells. J. Dent. Res. 86: 79-83, 2007.

${ }^{2}$ Arora, V., P. Arora, and A. K. Munshi. Banking stem cells from human exfoliated deciduous teeth (SHED): saving for the future. J. Clin. Pediatr. Dent. 33: 289-294, 2009.

${ }^{3}$ Asahina, I, T. K. Sampath, I. Nishimura and P. V. Hauschka. Human osteogenic protein-1 induces both chondroblastic and osteoblasic differentiation of osteoprogenitor cells derived from newbone rat calvaria. J. Cell Biol. 123: 921-933, 1993.

${ }^{4}$ Breitbart, A. S., D. A. Grande, R. Kessler, J. T. Ryaby, R. J. Fitzsimmons, and R. T. Grant. Tissue engineered bone repair of calvarial defects using cultured periosteal cells. Plast Reconstr. Surg. 101: 567-574, 1998.

${ }^{5}$ Cabral, M. C., M. A. Costa, and M. H. Fernandes. In vitro models of periodontal cells: a comparative study of long-term gingival, periodontal ligament and alveolar bone cell cultures in the presence of beta-glycerophosphate and dexamethasone. J. Mater. Sci. Mater. Med. 18: 1079-1088, 2007.

${ }^{6}$ Chung, I. H., T. Yamaza, H. Zhao, P. H. Choung, S. Shi, and Y. Chai. Stem cell 
property of postmigratory cranial neural crest cell their utility in alveolar bone regeneration and tooth development. Stem cells 27: 866-877, 2009.

${ }^{7}$ d'Aquino, R., A. De Rosa, V. Lanza, V. Tirino, L. Laino, A. Graziano, V. Desiderio, G. Laino, and G. Papaccio. Human mandible bone defect repair by the grafting of dental pulp stem/progenitor cells and collagen sponge biocomplexes. Eur. Cell. Mater. 18: 75-83, 2009.

${ }^{8}$ Graziano, A., R. d'Aquino, G. Laino, and G. Papaccio. Dental pulp stem cells: a promising tool for bone regeneration. Stem cell Rev. 4: 21-26, 2008.

${ }^{9}$ Hiraga, T., T. Ninomiya, A. Hosoya, M. Takahashi, and H. Nakamura. Formation of bone-like mineralized matrix by periodontal ligament cells in vivo: a morphological study in rats. J. Bone Miner. Metab. 27: 149-157, 2009.

${ }^{10}$ Hou, L. T., T. I. Li, C. M. Liu, B. Y. Liu, C. L. Liu, and H. W. Mi. Modulation of osteogenic potential by recombinant human bone morphogenic protein- 2 in human periodontal ligament cells: effect of serum, culture medium, and osteoinductive medium. J. Periodontal. Res. 42: 244-252, 2007.

${ }^{11}$ Iohara, K., L. Zheng, H. Wake, M. Ito, J. Nabekura, H. Wakita, H. Nakamura, T. Into, K. Matsushita, and M. Nakashima. A novel stem cell source for vasculogenesis in ischemia: subfraction of side population cells from dental pulp. Stem Cells 26: 
2408-2418, 2008.

${ }^{12}$ Iohara, K., M. Nakashima, M. Ito, M. Ishikawa, A. Nakashima, and A. Akamine. Dentin regeneration by dental pulp stem cell therapy with recombinant human bone morphogenetic protein 2. J. Dent. Res. 83: 590-595, 2004.

${ }^{13}$ Jäger, M., J. Fischer, W. Dohrn, X. Li, D. C. Ayers, A. Czibere, W. C. Prall, S. Lensing-Höhn, and R. Krauspe. Dexamethasone modulates BMP-2 effects on mesenchymal stem cells in vitro. J. Orthop. Res. 26: 1440-1448, 2008.

${ }^{14}$ Jørgensen, N. R., Z. Henriksen, O. H. Sørensen, and R. Civitelli. Dexamethasone, BMP-2, and 1,25-dihydroxyvitamin D enhance a more differentiated osteoblast phenotype: validation of an in vitro model for human bone marrow-derived primary osteoblasts. Steroids 69: 219-226, 2004.

${ }^{15}$ Jung, R. E., R. Glauser, P. Scharer, C. Hammerle, H. F. Sailer, and F. E. Weber. Effect of rhBMP-2 on guided bone regeneration in humans. Clin. Oral Implants Res. 14: 556-68, 2003.

${ }^{16}$ Kim, I. S., Y. M. Song, T. H. Cho, Y. D. Park, K. B. Lee, I. Noh, F. Weber, and S. J. Hwang. In vitro response of primary human bone marrow stromal cells to recombinant human bone morphogenic protein-2 in the early and late stages of osteoblast differentiation. Dev. Growth Differ. 50: 553-564, 2008. 
${ }^{17}$ Maegawa, N., M. Kawamura, M. Hirose, H. Yajima, Y. Takakura, and H. Ohgushi. Enhancement of osteoblastic differentiation of mesenchymal stromal cells cultured by selective combination of bone morphogenetic protein-2 (BMP-2) and fibroblast growth factor-2 (FGF-2). J. Tissue Eng. Regen. Med. 1: 306-313, 2007.

${ }^{18}$ Markopoulou, C. E., I. A. Vrotsos, H. N. Vavouraki, X. E. Dereka, and Z. S. Mantzavinos. Human periodontal ligament cell responses to recombinant human bone morphogenetic protein-2 with and without bone allografts. J. Periodontol. 74: 982-989, 2003.

${ }^{19}$ Matsubara, T., K. Suardita, M. Ishii, M. Sugiyama, A. Igarashi, R. Oda, M. Nishimura, M. Saito, K. Nakagawa, K. Yamanaka, K. Miyazaki, M. Shimizu, U. K. Bhawal, K. Tsuji, K. Nakamura, and Y. Kato. Alveolar bone marrow as a cell source for regenerative medicine: differences between alveolar and iliac bone marrow stromal cells. J. Bone Miner. Res. 20: 399-409, 2004.

${ }^{20}$ Matsui, S., H. Takeuchi, Y. Tsujimoto, and K. Matsushima. Effects of Smads and BMPs induced by Ga-Al-As laser irradiation on calcification ability of human dental pulp cells. J. oral. Sci. 50: 75-81, 2008.

${ }^{21}$ Miura, M., S. Gronthos, M. Zhao, B. Lu, F. W. Fisher, P. G. Robey, and S. Shi. SHED: stem cells from human exfoliated deciduous teeth. Proc. Natl Acad. Sci. USA 100: 
5807-5812, 2003.

${ }^{22}$ Nakamura, A., Y. Dohi, M. Akahane, H. Ohgushi, H. Nakajima, H. Funaoka, and Y. Takakura. Osteocalcin secretion as an early marker of in vitro osteogenic differentiation of rat mesenchymal stem cells. Tissue Eng. PartC Methods 15: 169-180, 2009.

${ }^{23}$ Nakamura, S., Y. Yamada, W. Katagiri, T. Sugito, K. Ito, and M. Ueda. Stem cell proliferation pathways comparison between human exfoliated deciduous teeth and dental pulp stem cells by gene expression profile from promising dental pulp. J. Endod. 35: 1536-1542, 2009.

${ }^{24}$ Patel, W., L. Zhao, P. Wong, B. B. Pradhan, H. W. Bae, L. Kanim, and R. B. Delamarter. An in vitro and in vivo analysis of fibrin glue use to control bone morphogenetic protein diffusion and bone morphogenetic protein-stimulated bone growth. Spine. J. 6: 397-403, 2006.

${ }^{25}$ Perka, C., O. Schultz, R. S. Spitzer, K. Lindenharyn, G. R. Burmester, and M. Sittinger. Segmental bone repair by tissue-engineered periosteal cell transplants with bioresorbable fleece and fibrin scaffolds in rabbits. Biomaterials 21: 1145-1153, 2000. ${ }^{26}$ Saito, T., M. Ogawa, Y. Hata, and K. Bessho. Acceleration effect of human recombinant bone morphogenetic protein-2 on differentiation of human pulp cells into odontoblasts. J. Endod. 30: 205-208, 2004. 
${ }^{27}$ Saito, Y., T. Yoshizawa, F. Takizawa, M. Ikegame, O. Ishibashi, K. Okuda, K. Hara, K. Ishibashi, M. Obinata, and H. Kawashima. A cell line with characteristics of the periodontal ligament fibroblasts is negatively regulated for mineralization and Runx2/Cbfa1/Osf2 activity, part of which can be overcome by bone morphogenetic protein-2. J. Cell Sci. 115: 4191-4200, 2002.

${ }^{28}$ Seo, B. M., M. Miura, S. Gronthos, P. M. Bartold, J. Brahim, M. Young, P. G. Robey, C. Y. Wang, and S. Shi. Investigation of multipotent postnatal stem cell from human periodontal ligament. Lancet 364: 149-155, 2004.

${ }^{29}$ Shi, S., P. M. Bartold, M. Miura, B. M. Seo, P. G. Robry, and S. Gronthos. The efficary of mesenchymal stem cells to regenerate and repair dental structures. Orthod. Craniofac. Res. 8: 191-199, 2005.

${ }^{30}$ Woods, E. J., B. C. Perry, J. J. Hockema, L. Larson, D. Zhou, and W. S. Goebel. Optimized cryopreservation method for human dental pulp-derived stem cells and their tissues of origin for banking and clinical use. Cryobiology 59: 150-157, 2009.

${ }^{31}$ Yamada, Y., M. Ueda, T. Naiki, M. Takahashi, K. Hata, and T. Nagasaka. Autogenous injectable bone for regeneration with mesenchymal stem cells and platelet-rich plasma: tissue-engineered bone regeneration. Tissue Eng. 10: 955-964, 2004.

${ }^{32}$ Yang, X., P. M. van der Kraan, Z. Bian, M. Fan, X. F. Walboomers, and J. A. Jansen. 
Mineralized tissue formation by BMP2-transfected pulp stem cells. J. Dent. Res. 88:

1020-1025, 2009.

${ }^{33}$ Young, C. S., H. Abukawa, R. Asrican, M. Ravens, M. J. Troulis, L. B. Kaban, J. P.

Vacanti, and P. C. Yelick. Tissue-engineered hybrid tooth and bone. Tissue Eng. 11:

1599-1610, 2005. 


\section{FIGURE LEGENDS}

FIGURE 1. Morphological observations and cell proliferation rate of DPCs and PDLCs. (a) Cultured DPCs in $\alpha$-MEM with 10\% FBS (100×). (b) Cultured PDLCs in $\alpha$-MEM with $10 \%$ FBS $(100 \times)$. Both cell types showed similar morphology with a characteristic spindle shape. (c) DPCs and PDLCs were cultured in 96-well plates at initial density of $1.0 \times 10^{4}$ cells per well. The proliferation of each cell type was examined with an MTT assay. DPCs are indicated by squares, and PDLCs are indicated by circles.

FIGURE 2. Alkaline phosphatase (ALP) activity of DPCs (a) and PDLCs (b) cultured in the various conditions. Both cell types were cultured in normal serum-conditioned $\alpha$-MEM, or osteogenic medium with $0-300 \mathrm{ng} / \mathrm{ml} \mathrm{rhBMP2}$ for 13 days and were analyzed for ALP activity on day 14. Concentrations of 0-300 ng/ml rhBMP2 enhanced ALP activity in a dose-dependent manner. The asterisk represents statistical significance $(p<0.05)$ between the group of interest and the control or cells grown in osteogenic medium.

FIGURE 3. Alizarin red staining of cultured DPCs and PDLCs in normal serum-conditioned $\alpha$-MEM, or osteogenic medium with or without $300 \mathrm{ng} / \mathrm{ml}$ rhBMP2 for 13 days. On day 14, layers formed by both cell types were stained with 
Alizarin red to visualize mineral deposits. Alizarin red staining for calcium showed vanishingly calcified nodules from DPCs (a) and PDLCs (d). Calcified nodules were detectable in cultures of DPCs (b) and PDLCs (e) treated with osteogenic medium. Osteogenic medium containing $300 \mathrm{ng} / \mathrm{ml} \mathrm{rhBMP2}$ remarkably increased the formation of calcified nodules in cultures of DPCs (c) and PDLCs (f).

FIGURE 4. Expression of osteoblastic marker genes at day 14 of culture. DPCs and PDLCs were cultured in normal serum-conditioned $\alpha$-MEM, or osteogenic medium with or without $300 \mathrm{ng} / \mathrm{ml}$ rhBMP2. We detected transcripts for osteocalcin (ocn) (231 bp), osteopontin (opn) (275 bp), dentin matrix protein-1 (dmp1) (331 bp), and glyceraldehyde phosphate dehydrogenase (gapdh) (452 bp). Each rhBMP2-treated cell type showed clearly increased expression of ocn, opn, and $d m p 1$.

FIGURE 5. Histological observation of in vivo bone formation 8 weeks after transplantation. (a) Transplants of hydroxylapatite (HA) with $300 \mathrm{ng} / \mathrm{ml} \mathrm{rhBMP2}$ alone without cells formed no bone $(100 \times)$. (b) Transplants of hydroxylapatite (HA) with untreated DPCs formed no bone $(100 \times)$. (c) Limited bone-like tissues were observed in transplants of HA with DPCs treated with osteogenic medium (100×). (d) Transplants of HA with DPCs treated with 300ng/ml rhBMP2 formed bone-like 
tissues $(100 \times)$. (e) Transplants of HA with DPCs treated with $300 \mathrm{ng} / \mathrm{ml} \mathbf{~ r h B M P 2}$ in osteogenic medium formed abundant bone-like tissues (100×). (f) Osteocyte inclusions were observed in the bone-like tissues $(200 \times)$. (g) Transplants of HA with $300 \mathrm{ng} / \mathrm{ml} \mathrm{rhBMP2}$ alone without cells formed no bone $(100 \times)$. (h) Transplants of HA with untreated PDLCs formed no bone (100×). (i) Limited bone-like tissues were observed in transplants of HA with PDLCs treated with osteogenic medium (100×). (j) Transplants of HA with PDLCs treated with 300ng/ml rhBMP2 formed bone-like tissues $(100 \times)$. (k) Transplants of HA containing PDLCs treated with 300ng/ml rhBMP2 in osteogenic medium formed significant amounts of bone-like tissues $(100 \times)$. (l) Osteocyte inclusions were observed in the bone-like tissues $(200 \times)$.

FIGURE 6. The amount of newly formed bone-like tissues. The amount was analyzed with NIH J Image software (NIH, Bethesda, MD, USA). The bone area is expressed as the percentage of the total area. Transplantation of both control cell types [Control cell transplantation] and non-cell transplantation [Non cell] formed no mineralized tissues. Both cells types treated with osteogenic medium formed minimal bone-like tissues [Supple], and cells treated with $300 \mathrm{ng} / \mathrm{ml} \mathbf{~ r h B M P 2}$ formed bone-like tissues in approximately $20 \%$ of the whole area $[300 \mathrm{ng} / \mathrm{ml}$ 
BMP2]. However, abundant bone-like tissue formation (approximately $60 \%$ of the whole area) was observed in samples of both cell types that had been treated with osteogenic medium containing $300 \mathrm{ng} / \mathrm{ml} \mathrm{rhBMP2}$ [300 ng/mlBMP2 + Supple]. The asterisk indicates a significant difference $(p<0.05)$. 


\section{FIGURE 1.}
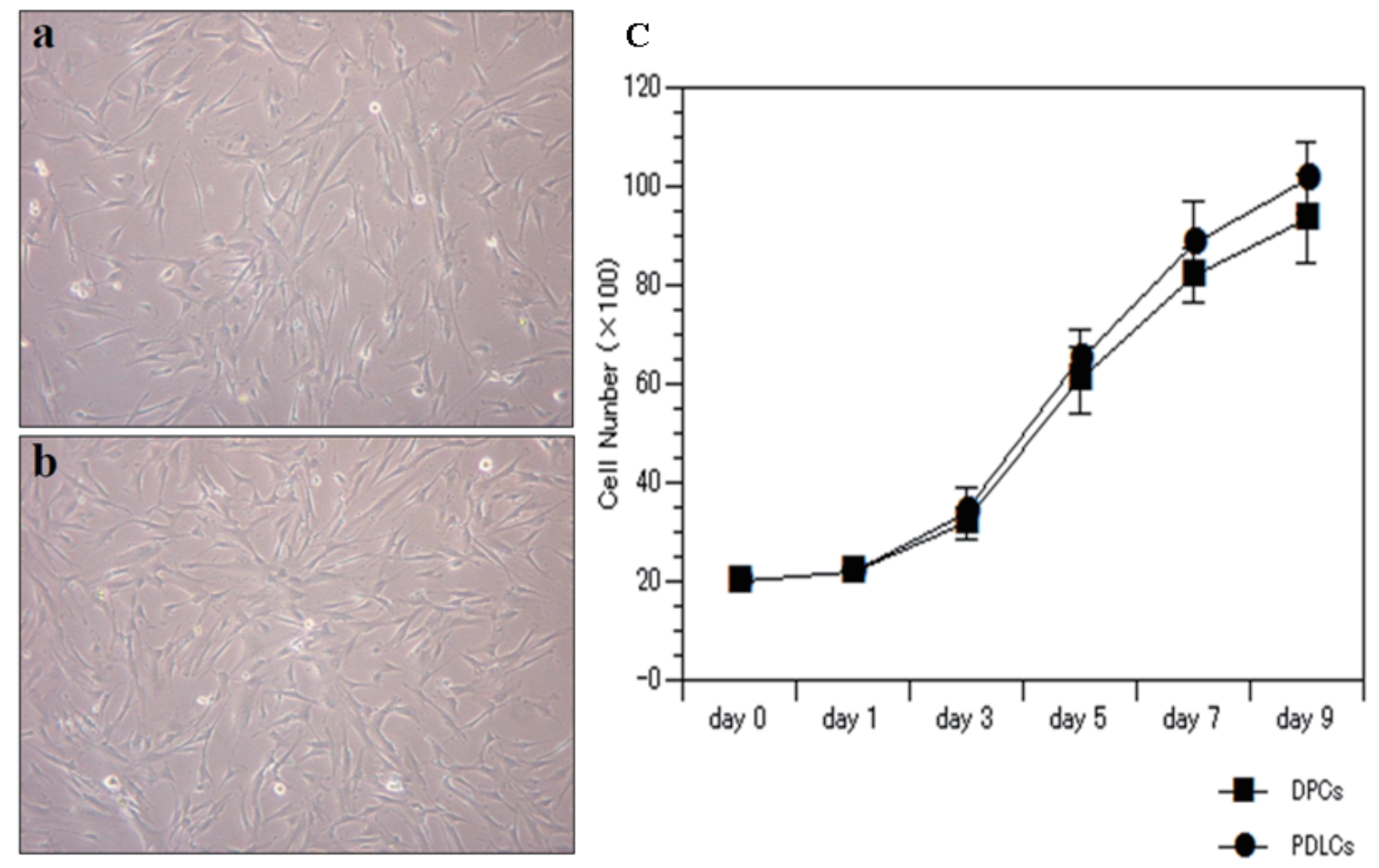

Ikeda H 


\section{FIGURE 2.}

a

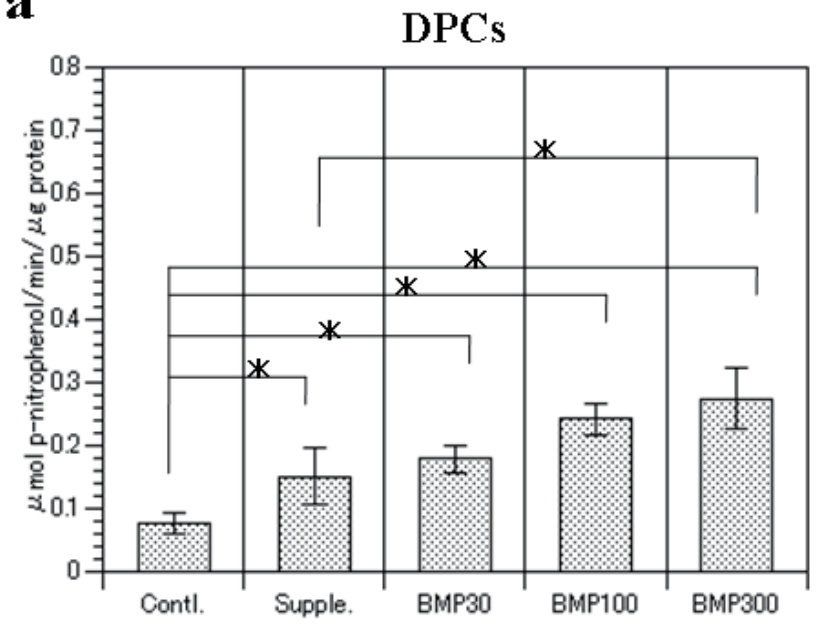

b

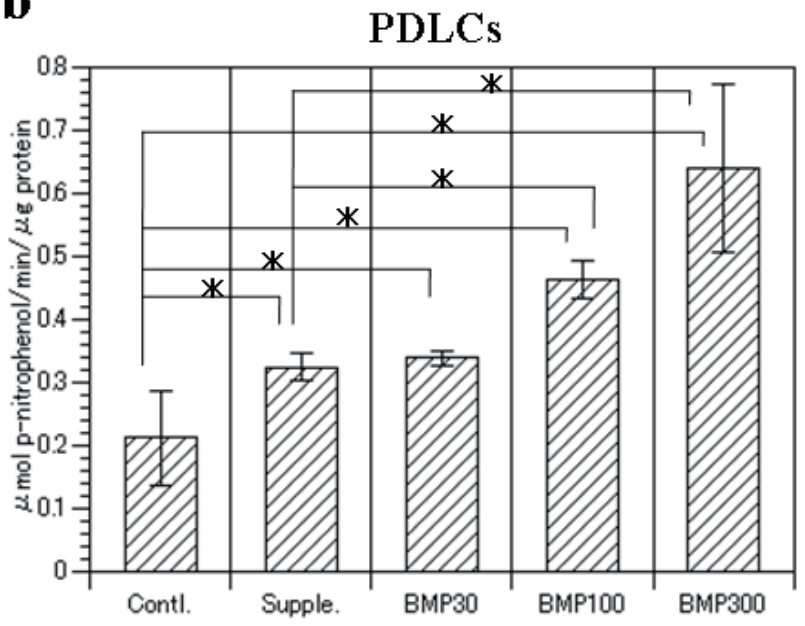

Contl. : non-treatment,

$* \mathbf{p}<0.05$

Supple. : osteo-inductive supplements (Dex $+\beta-$ Gly $+A A)$, BMP30 : 30ng/ml BMP2 + Supple.,

BMP100: 100ng/ml BMP2 + Supple.,

BMP300 : 300ng/ml BMP2 + Supple.

Ikeda $\mathrm{H}$ 


\section{FIGURE 3.}

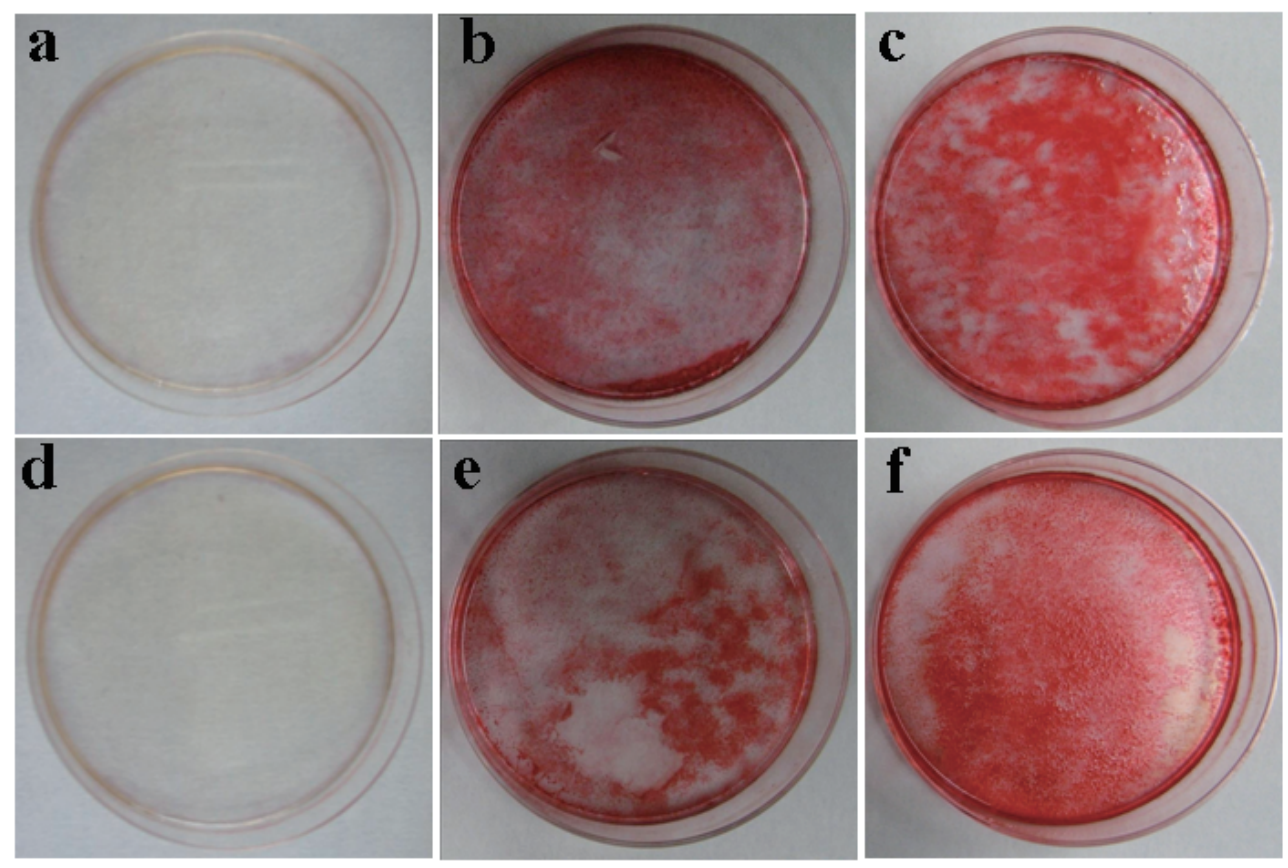

Ikeda $\mathrm{H}$ 


\section{FIGURE 4.}

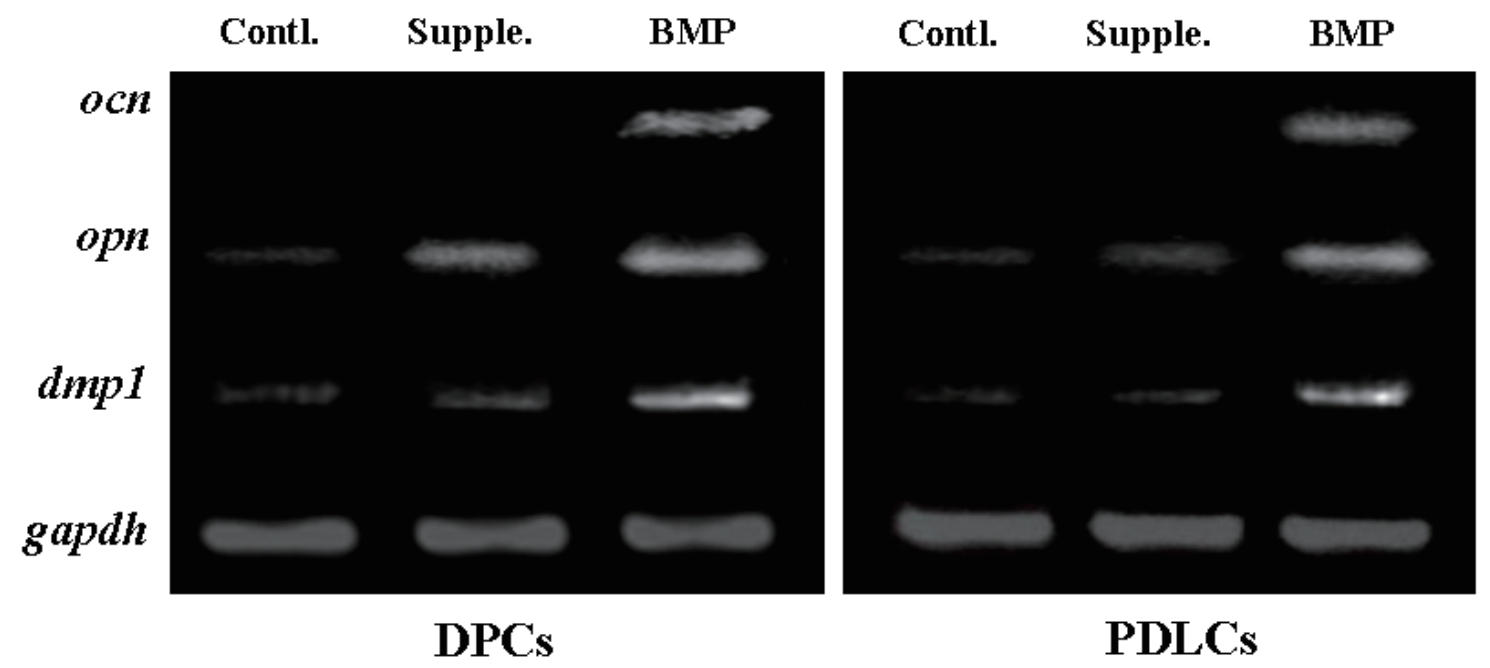

Contl. : non-treatment,

Supple. : osteo-inductive supplements (Dex $+\beta-$ Gly + AA),

BMP : 300ng/ml BMP2 + Supple.

Ikeda $\mathrm{H}$ 


\section{FIGURE 5.}
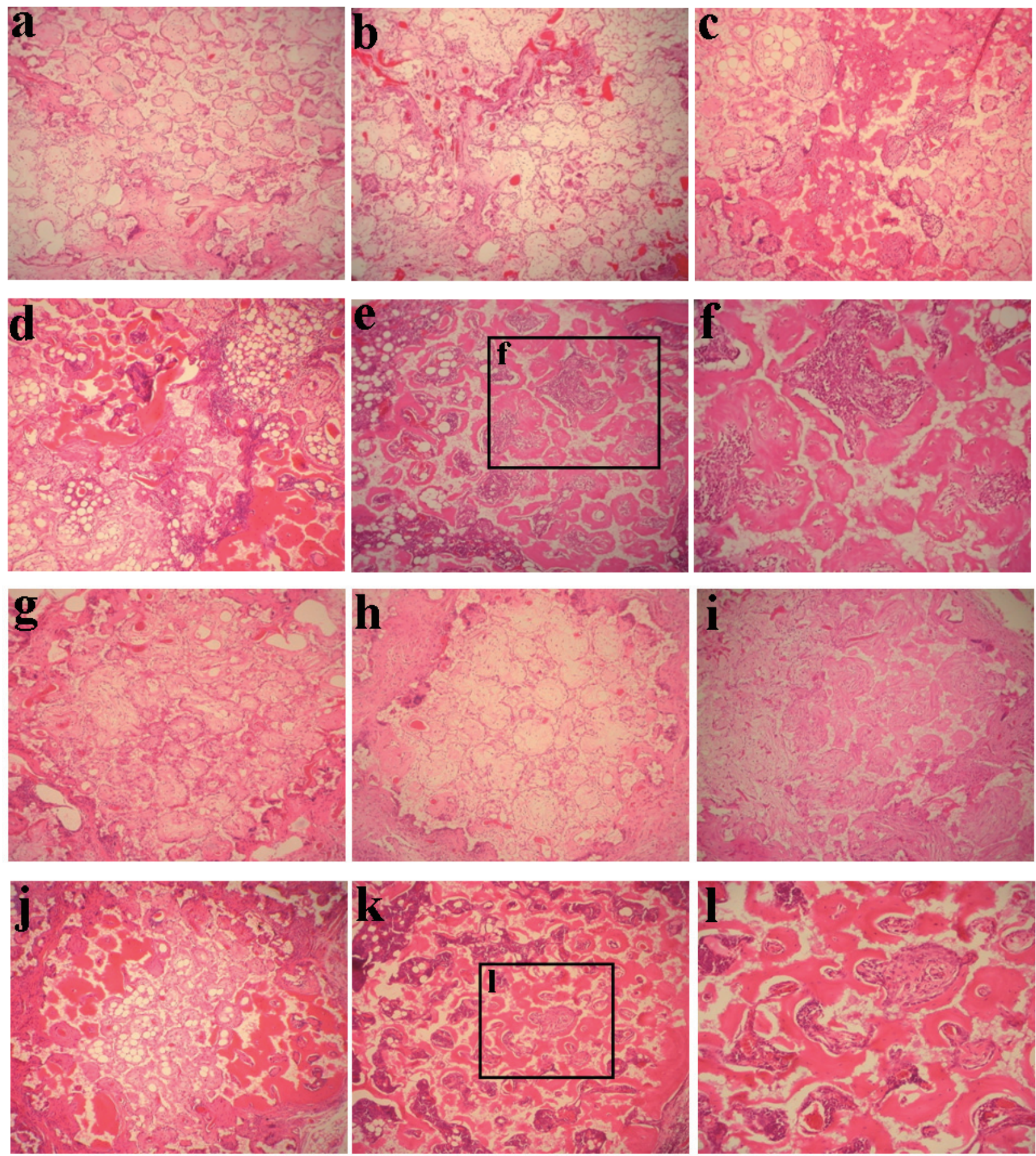

Ikeda $\mathrm{H}$ 
FIGURE 6.

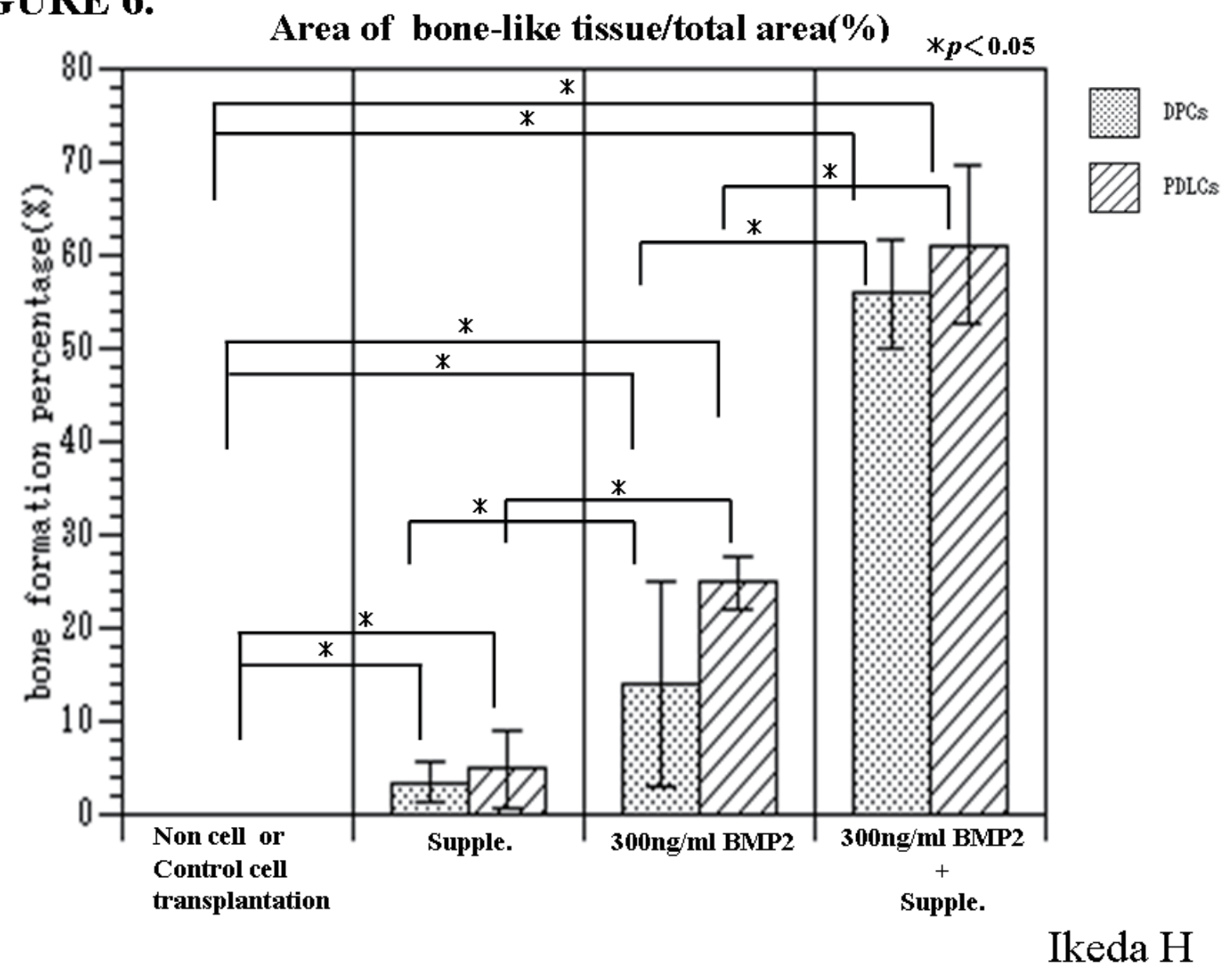




\section{Table.1}

Sequence of primer pairs used for semiquantitative RT-PCR (ocn osteocalcin, opn osteopontin, dmpl dentin matrix protein 1, gapdh glyceraldehyde-3-phosphate dehydrogenase)

\begin{tabular}{lll}
\hline gene & Sense primer & Antisense primer \\
\hline ocn & $5^{\prime}$-CATGAGAGCCCTCACA-3' & $5^{\prime}$-AG AGC GAC ACC CTA GAC-3' \\
opn & $5^{\prime}$-GACCCATCTCAGAAGCAGAA-3' & $5^{\prime}$-GTGGGAAAATCAGTGACCAG-3' \\
dmpl & $5^{\prime}$-GACTGCCAAGACGGCTATTA-3' & 5'-TCATGGACACCCAATAGCTT-3' \\
gapdh & $5^{\prime}$-ACCACAGTCCATGCCATCAC-3' & 5'-TCCACCACCCTGTTGCTGTA-3' \\
\hline
\end{tabular}

Ikeda $\mathrm{H}$ 